\title{
The Mediating Role of Job Burnout in the Relationship between Role Conflict and Job Performance: An Empirical Research of Hotel Frontline Service Employees in China
}

\author{
Li Zhou ${ }^{1}$, Liu Yong ${ }^{2}$ \& Luo Danling ${ }^{2}$ \\ ${ }^{1}$ Shenzhen Tourism College, Jinan University, Shenzhen, Guangdong, China \\ ${ }^{2}$ Management School, Jinan University, Guangzhou, Guangdong, China \\ Correspondence: Liu Yong, Management School, Jinan University, Guangzhou, Guangdong, China. E-mail: \\ liuyong0815@foxmail.com
}

\author{
Received: July 29, $2014 \quad$ Accepted: August 15, $2014 \quad$ Online Published: August 24, 2014 \\ doi:10.5539/ijps.v6n3p88 URL: http://dx.doi.org/10.5539/ijps.v6n3p88
}

\begin{abstract}
As an increasingly fierce competition in hospitality industry, the service quality of frontline service employees determine the success of hotels. Therefore, it is significant to improve the service quality of frontline service employees by enhancing their job performance. According to the conservation of resources theory, frontline service employees are easily confronted with role conflicts, which result in job burnout and negatively influence job performance. However, the relationship between "role conflict-burnout-job performance" is not consistent according to previous studies. Motivated by the theoretical concern to further understanding of this subject, the purpose of this article is to explore whether role conflict will affect job performance through job burnout. Based on the data of 189 frontline service employees from 18 budget hotels, this study tests the hypotheses. The results show that: (1) Role conflict is positively related to burnout; (2) Both role conflict and burnout are negatively related to job performance; (3) Burnout partially mediated the relationship between role conflict and job performance. Implications for practices are discussed.
\end{abstract}

Keywords: role conflict, burnout, job performance, frontline service employee

\section{Introduction}

With the rapid development of China's hotel industry in recent years, hotel industry becomes increasingly competitive. Hotel mangers realize that they have to provide high performance services and meet customer requirements to establish and maintain long-term relationship with customers. Wide majority of the hotels become aware that first-class facilities are simply the foundation of customer value-delivery, and frontline service employees are the most important links in this process, their service quality directly determines the destiny of hotels (Karatepe et al., 2006).

In high-stress work atmosphere, frontline service employees need to play different social roles to satisfy different job demands from customers, co-workers and managers. Thus, frontline service employees are likely to experience role conflicts when they are incapable of satisfying all job demands at the same time (Churchill et al., 1976). In addition, this kind of negative emotions would lead frontline service employees to experience burnout. All of these not only affect the frontline service employees' job satisfaction and mental health, but also influence job performance negatively (Maslach et al., 2001).

According to the service profit chain theory, service employees' job performance would influence service quality and further affect customer satisfaction and business performance. In other words, employees of high performance will improve their service quality. Thus, hotel managers need to seek effective ways to enhance the performance and job satisfaction of frontline service employees from the perspective of human resources management (Wen, 2011).

Under this background, the present study develops and tests a research model to examine the mediating influence of job burnout on the relationship between role conflict and job performance (whether role conflict will affect job performance through job burnout) among hotel frontline service employees. 
In Section 2, the relevant literature reviews are presented. Then, the theoretical background and hypothesized relationships are proposed. Following this, the research methodology and results of the empirical study are discussed. The study concludes with implications of the results and suggestions for future research. Figure 1 schematically depicts this objective.

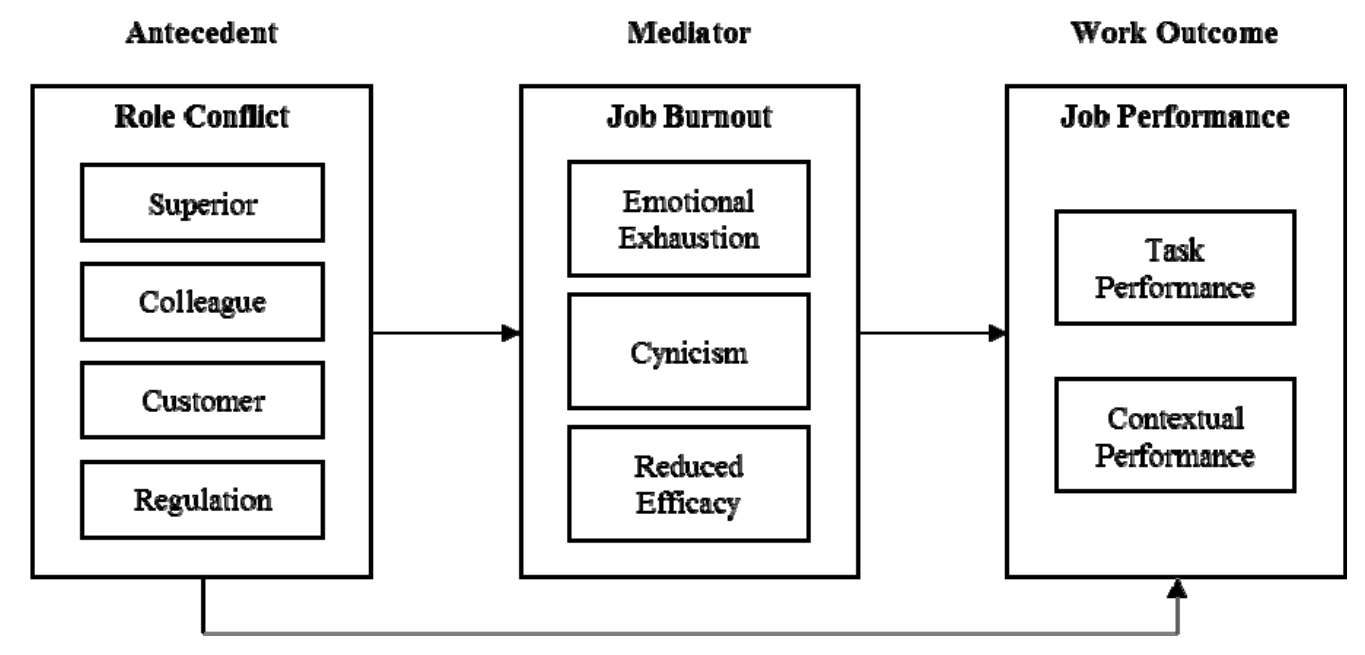

Figure 1. Hypothesized model

\section{Literature Review and Hypotheses}

\subsection{Role Conflict}

There are two key aspects of role stress: role conflict and role ambiguity (Kahn et al., 1964; Rizzo et al., 1970). Role conflict is a conflict among the roles corresponding to two or more statuses, it is "the degree of incongruity or incompatibility of expectations associated with the role" (Kim et al., 2009). Due to the boundary-spanning roles, multiple role expectations (superiors, colleagues and customers) easily result in frontline service employees' role conflicts where employees often play multiple roles.

\subsection{Job Burnout}

In addition, frontline service employees experience burnout under the stress of role conflict. The study on job burnout has attained substantial research attention and it is defined as "a syndrome of emotional exhaustion and cynicism that occurs frequently among individuals who do people-work of some kind" (Maslach \& Jackson, 1981). In this sense, burnout is a prolonged response to chronic stressors in the workplace (Maslach et al., 1996). There are three core dimensional syndromes of the job burnout experience: emotional exhaustion, cynicism/depersonalization and reduced efficacy/reduced personal accomplishment. Emotional exhaustion is mainly related to an individual's experience of stress, which is, in turn, related to a decline in emotional and physical resources. Cynicism is an attempt to create distance between oneself and service recipients by actively ignoring the qualities that make them unique and attract people. Reduced efficacy is the feeling of ineffectiveness and lack of achievement and productivity at work (Maslach et al., 2001). This theoretical framework continues to be the predominant one in the burnout field.

\subsection{Job Performance}

Job performance is about whether a person performs their job well. Borman and Motowidlo (1993) divided job performance into task and contextual behaviors. Task performance describes obligatory behaviors, thus it can be defined as the effectiveness of job incumbents' activities that contribute to the organization's technical core either directly by implementing a part of its technological process, or indirectly by providing it with needed materials or services (Borman \& Motowidlo, 1993). Contextual performance are behaviors that do not fulfill specific aspects of the job's required role, and it includes such activities as helping others with their jobs, supporting the organization and volunteering for additional work and responsibility (Borman et al., 2001). The two-dimensional model of job performance is also effective under the context of Chinese culture through the study of Wang et al. (2003). 


\subsection{Conservation of Resources Theory}

Up to now, individual studies and meta-analyses have found conservation of resources (COR) theory to be a major explanatory model for understanding the stress process at work, especially the relationships of role conflict, job burnout and job performance (Westman, 2004). According to COR theory, "individuals are seen as motivated to obtain, retain, foster and protect those things they value", and resources are defined as "those objects, personal characteristics, conditions, or energies that are valued by the individual or that serve as a means for attainment of these objects, personal characteristics, conditions, or energies"(Hobfoll, 1989, 2001).

\subsection{Role Conflict and Job Burnout}

Based on COR theory, job burnout is most likely to occur when the resources of individuals are threatened with loss, lost, or when individuals fail to gain resources after a significant resource investment (Hobfoll, 2001). Thus, job burnout is one of the sequelae of stressful work circumstances. Through above analysis, we can see that role conflict is one kind of role stress, when individuals are incapable of coping with conflicting demands on their resources, it would cause ongoing resource depletion, then role conflict could ultimately result in job burnout (Lee \& Ashforth, 1996).

Many empirical researches have proved that role conflict consistently shows a moderate to high correlation with job burnout (Maslach et al., 2001). Piko (2006) found evidence in health care staff that role conflict was a factor contributing positively to emotional exhaustion and depersonalization scores. Karatepe and Uludag (2008) also reported similar findings that role conflict and exacerbated emotional exhaustion and depersonalisation. Thus, the following hypothesis is proposed:

\section{Hypothesis 1: Role conflict is positively related to hotel frontline service employees' job burnout.}

\subsection{Role Conflict and Job Performance}

In the earlier studies, scholars have discovered that role conflict is related to job performance, but the studies they found reported mixed results. Consequently, disagreement exists as to what can be concluded about the role conflict and job performance.

First, some scholars believe that there are no significant association between role conflict and job performance. Brown an Peterson (1993) found that role conflict did not have a significant direct effect on sales performance. Second, some research findings showed that role conflict have a significant negative correlation with job performance. MacKenzie et al. (1998) argued that role conflict was related negatively to in-role performance of salesperson through empirical study. Tubre and Collins (2000) conducted a meta-analysis of correlations between role conflict and job performance, the result showed that a negligible relationship was observed for role conflict and job performance. Third, several empirical studies have provided evidence of positive relationship between role conflict and job performance. Babakus et al. (1999) argued that a positive relationship between role conflict and job performance of field salespeople from a large international services organization. Karatepe and Uludag's (2008) study showed that role conflict increases frontline hotel employees' job performance. Considering that salespeople and frontline service employees all belong to boundary spanners, this study argue that the relationship between role conflict and job performance is tenable for frontline service employees.

However, according to COR theory, when employees are confronted with resource depletion caused by role conflict, they would focus on retaining or recovering resources, it may result in interpersonal alienation and low job performance. Thus, the following hypothesis is proposed:

\section{Hypothesis 2: Role conflict is negatively related to hotel frontline service employees' job performance.}

\subsection{Job Burnout and Job Performance}

The significance of researches on job burnout lies in its effect on work outcomes, especially job performance. By examining the existing literature, results indicate that the effects of burnout on performance have been more stable in general. Maslach et al. (2001) argued that burnout leads to lower productivity and effectiveness at work, and what's worse, people who are experiencing burnout can have a negative impact on their colleagues, both by causing greater personal conflict and by disrupting job tasks. But in terms of three dimensions of burnout, there are different, and perhaps difficult to reconcile, views of the relationship between every dimension of job burnout and performance. Wright and Bonett's (1997) study showed that emotional exhaustion was negatively to work performance, however, the results failed to establish relationships among work performance, depersonalization and diminished personal accomplishment. Advani et al. (2005) also showed similar results about the relationships of the burnout dimensions with job performance in the context of Indian software services industry. Recently, Karatepe and Uludag's (2008), in their empirical study, indicated that diminished 
personal accomplishment exerted a significant negative influence on job performance whereas the rest of the burnout dimensions did not. Therefore, the relationship between job burnout and job performance is unstable, further testing is needed.

COR theory argues that when employees suffer from serious burnout, their job performance starts to decline. This is because employees no longer conserve appropriate or enough resources to deal with job tasks by experiencing the individual's job burnout. Thus, the following hypothesis is proposed:

Hypothesis 3: Job burnout is negatively related to hotel frontline service employees' job performance.

\subsection{Mediating Role of Job Burnout}

The hypothesized mediating influence of job burnout on the relationship between role conflict and job performance is predicated on the notion that, as a main stressor in work environment, role conflict causes job burnout, and the negative effect of burnout in turn influences work outcomes. Above hypothesis has been tested indirectly by many scholars' studies (Singh, 1993; Singh et al., 1994; Zhang \& Niu, 2013). First, although the relationship between role stress and job result is unstable, but the influence of job burnout on work outcomes is relatively consistent. Second, accumulation of pressure caused by role conflict would result in job burnout, it simultaneously also had many negative effects on work outcomes. Furthermore, due to the obvious fluctuations regarding the immediate impact of role stress on work outcomes, it implies that there are some potential variables which contribute to the phenomenon, and the intervention of job burnout could be able to explain more clearly the mechanism of role conflict and workouts. Thus, the following hypothesis is proposed:

Hypothesis 4: Job burnout mediates the relationships between role conflict and job performance.

\section{Methods}

\subsection{Sample and Procedures}

Participants in the current study were frontline service employees of 18 budget hotels located in a major city in southern China. Respondents were informed that the survey aimed to examine their actual true feeling in daily work and were assured of the confidentiality of responses. The questionnaires were distributed to 271 employees that took place about one month. 189 valid questionnaires were returned for response rates of $69.7 \%$.

Of the 189 respondents, $56.7 \%$ percent were female. $23.9 \%$ of the respondents were married whereas the rest were single or divorced. The age group with the highest proportion is under $25(54.0 \%) .77 .8 \%$ of the respondents had tenures of less than two year. $85.7 \%$ of the respondents had college degree and below education. $59.3 \%$ of respondents were from front desk agents.

\subsection{Measures}

With the exception of job burnout scales, the measures were originally constructed in English. To assure the equivalence of the measures in the Chinese and the English versions of the survey instrument, we performed a standard translation and back-translation procedure (Brislin, 1980). The Chinese version was subsequently pilot-tested on hotel interns who were not included in the final sample. On the basis of the feedback, we reworded a few items to ensure clarity. The response format is a 5-point Likert-type scale $(1=$ totally disagree to $5=$ totally agree).

Role conflict. We used Karatepe and Uludag's (1989) five-item scale to measure role conflict from the perspectives of regulations, superiors, colleagues and customers. Sample items were, "I work with two or more groups who operate differently" and "I receive incompatible requests from two or more people." The scale's reliability was .90 .

Job burnout. We used a fifteen-item scale developed by Li (2005) to measure job burnout (Chinese Maslach Burnout Inventory, CMBI), which has previously been tested in a Chinese context. Sample items were, "I feel emotionally drained from my work", "I feel recipients blame me for some of their problems" and "I feel exhilarated after working closely with my recipients." The scale's reliability was .89 .

Job performance. We used a five-item scale by Karatepe a Uludag (2008) to measure job performance. This scale has previously been used in a Chinese context (Chen \& Yu, 2011). Sample items were, "I am a top performer" and "I know what my customers expect better than others." The scale's reliability was .83 .

Controls. We controlled for six demographic variables that might potentially confound the results. Previous research has shown age, gender, marital status and tenure to be related to job burnout (Maslach et al., 2001). Age and tenure were measured using five-point scales. Education was measured using a four-point scale. Gender was coded 1 for "male" and 0 for "female." Marital status was coded 1 for "married" and 0 for "single or divorced." 
Types of work were also coded as a dummy variable $(0=$ front desk agents and $1=$ food servers or housekeeping department etc.).

\subsection{Data Analysis}

Following Baron and Kenny's (1986) recommended conditions for establishing mediation, we conducted regression analysis to test Hypothesis 1 to Hypothesis 4 using SPSS 21.0. Control variables were included in all analyses.

\section{Results}

Table 1 presents the means, standard deviations, and correlations among the study variables and the controls. Table 2 presents results of the regression analysis.

\subsection{Descriptive Statistics}

As shown in Table 1, all variables were significantly correlated. Role conflict was positively correlated with job burnout $(\mathrm{r}=.54, p<.001)$. Both role conflict and job burnout were negatively correlated with job performance $(\mathrm{r}$ $=-.44, p<.001 ; \mathrm{r}=-.35, p<.001$, respectively). All Cronbach's alpha values were within the acceptable range.

Table 1. Means, standard deviations, reliabilities, and correlations among study variables

\begin{tabular}{cccccc}
\hline Varible & Mean & s.d. & 1 & 2 & 3 \\
\hline 1.Role conflict & 2.33 & .80 & $(.90)$ & & \\
2.Job burnout & 2.43 & .52 & $.54^{* *}$ & $(.89)$ & \\
3.Job performance & 3.32 & .60 & $-.44^{* *}$ & $-.35^{* *}$ & $(.83)$ \\
\hline
\end{tabular}

Note. $\mathrm{N}=189 ; * p<.05, * * p<.01, * * * p<.001$.

\subsection{Hypothesis Tests}

Tables 2 reports the results of Hypotheses 1 to Hypothesis 4. As shown in Model 1 of Table 2, role conflict had a positive and statistically significant effect on job burnout $(\beta=.33, p<.001)$. Thus, Hypothesis 1 was supported. As shown in Model 2 of Table 2, role conflict had a negative and statistically significant effect on job performance $(\beta=-.31, p<.001)$. Thus, Hypothesis 2 was supported. As shown in Model 3 of Table 2, job burnout had a negative and statistically significant effect on job performance $(\beta=-.39, p<.001)$. Thus, Hypothesis 3 was supported.

Pertaining to the mediated hypothesis, the support for Hypothesis 1 to Hypothesis 3 respectively confirmed two of the conditions for testing mediation (Baron \& Kenny, 1986). However, since role conflict continued to be significantly related to job performance in model $4(\beta=-.31 \rightarrow-.24, p<.001 \rightarrow .005)$, the third condition for mediation was only partially supported. Thus, Hypothesis 4 received partial support.

Table 2. Results of regression analysis for mediation

\begin{tabular}{lcccc}
\hline & Job burnout & $\begin{array}{c}\text { Job } \\
\text { performance }\end{array}$ & $\begin{array}{c}\text { Job } \\
\text { performance }\end{array}$ & $\begin{array}{c}\text { Job } \\
\text { performance }\end{array}$ \\
\cline { 2 - 5 } & Model 1 & Model 2 & Model 3 & Model 4 \\
\hline Intercept & $1.58^{* * *}$ & $3.90^{* * *}$ & $4.04^{* * *}$ & $4.22^{* * *}$ \\
Controls & & & & \\
Gender & .03 & .14 & $.18^{*}$ & .15 \\
Marital status & -.08 & .08 & .07 & .06 \\
Age & .13 & .02 & .07 & .04 \\
Tenure & $-.09 *$ & -.01 & -.01 & -.03 \\
Education & .06 & .03 & .05 & .05 \\
Work type & -.04 & -.06 & -.12 & -.07 \\
\hline
\end{tabular}




\begin{tabular}{ccccc}
\hline Variables & & & \\
Role conflict & $.33^{* * *}$ & $-.31^{* * *}$ & & $-.24^{* * *}$ \\
Job burnout & & & $-.39^{* * *}$ & $-.21^{*}$ \\
Overall $R^{2}$ & .33 & .22 & .17 & .24 \\
Adjusted $R^{2}$ & .30 & .18 & .14 & .20 \\
Overall model $F$ & $62.71^{* * *}$ & $34.12^{* * *}$ & $22.28^{* * *}$ & $4.93^{* * *}$ \\
Note. $\mathrm{N}=189 ; * p<.05, * * p<.01, * * * p<.001$. &
\end{tabular}

\section{Discussion}

\subsection{Research Conclusions}

The results of the study revealed that role conflict and job burnout were related to affect job performance of hotel frontline service employees.

As mentioned above, hotel frontline service employees, as boundary spanners, are easily affected by fulfilling expectations from customers on the service stage and organizations behind the scenes during service interactions. Thus, they are more likely to suffer from stress and experience burnout. However, the relationships of role conflict and job burnout on job performance are not stable from the former studies, especially for hotel frontline service employees. For this reason, this study developed and tested an empirical research that investigated the effects of role conflict and burnout on job performance by using a sample of hotel frontline service employees. The results of the study follows: First, role conflict was positively to job burnout. Second, role conflict and job burnout were negatively related to affect job performance. Third, job burnout partially mediated the influence of role conflict on job performance.

In other words, role conflict inhibits motivation of employees, further prompts them to take conservative ways and just fulfill in-role behaviors in daily work. If the conflicting feelings exist for a long time, it would cause ongoing resource depletion, then role conflict could result in job burnout. Finally, above negative emotion experiences would badly affect job performance and service quality ultimately.

\subsection{Managerial Implications}

The major difference between service and manufacturing industry is that frontline service employees' service quality has become a part of the work outcomes and profit sources. Thus the inner feelings of hotel frontline service employees, especially the negative emotions, deserve much more attention and consideration from hotel managers.

Based on the question, the results of our study have several managerial implications. First, from the perspective of conflicting demands from internal organization, in the daily management, hotel managers should focus their effort on creating a supportive atmosphere to encourage the interpersonal communication and cooperation among employees. This helps employees understand expectations from managers and such efforts may potentially help employees understand expectations of frontline services, thus can decrease the frontline service employees' role conflict in the workplace. In addition, hotel managers should clarify the roles and responsibilities of each individual, and try to prevent mutually making excuses among peers. Second, from the perspective of organization-customer conflicting demands, since the demand of clients is growingly individual and diversified in hotel industry, the hotel managers should provide frontline service employees with more psychological and material resources and further empower them with the flexibility to respond instantly in instant customerization, therefore to avoid and eliminate the role conflicts caused from organization-customer conflicting expectations. Finally, from the perspective of activating job burnout, our findings of the mediating influence of job burnout suggest that organizations should sensitize hotel managers to the effects of human resource management practices to diminish employees' burnout. According to COR theory, hotel managers could supplement or restore frontline service employees' psychological and material resources through reasonable salary system, as well as proper training, benefits, insurance mechanisms. Hotel managers can also resort to Employee Assistance Program (EAP) to help employees deal with personal problems through providing psychological and career consultation, and then help them to obtain pleasurable work experiences and improve efficiency. 


\section{Acknowledgements}

This work was supported by the Experimental Research on Talents Interdisciplinary Cultivation Model of International Cooperation - The Case of Discipline of Tourism Management (DIA85514011).

\section{References}

Advani, J. Y., Garg, A. K., Jagdale, S., \& Kumar, R. (2005). Antecedents and Consequences of "Burnout" In Services Personnel: A Case of Indian Software Professionals. South Asian Journal of Management, 12(3), 21-34. Retrieved from http://papers.ssrn.com/sol3 /papers.cfm?abstract_id=882390

Babakus, E., Cravens, D. W., Johnston, M., \& Moncrief, W. C. (1999). The role of emotional exhaustion in sales force attitude and behavior relationships. Journal of the Academy of Marketing Science, 27(1), 58-70. http://dx.doi.org/ 10.1177/0092070399271005

Baron, R. M., \& Kenny, D. (1986). The Moderator-mediator Variable Distinction in Social Psychological Research: Conceptual, Strategic and Statistical Considerations. Journal of Personality and Social Psychology, 51, 1173-1182. http://dx.doi.org/10.1037/0022-3514.51.6.1173

Borman, W. C., \& Motowidlo, S. M. (1993). Expanding the criterion domain to include elements of contextual performance. Personnel selection in organizations; San Francisco: Jossey-Bass.

Borman, W. C., Penner, L. A., Allen, T. D., \& Motowidlo, S. J. (2001). Personality predictors of citizenship performance. International Journal of Selection and Assessment, 9(1-2), 52-69. http://dx.doi.org/10.1111/1468-2389.00163

Brislin, R. W. (1986). Translation and content analysis of oral and written materials. In H. C. Triandis, \& J. W. Berry (Eds.), Handbook of cross-cultural psychology (vol. 2, pp. 389-444). Boston: Allyn \& Bacon.

Brown, S. P., \& Peterson, R. A. (1993). Antecedents and consequences of salesperson job satisfaction: Meta-analysis and assessment of causal effects. Journal of Marketing Research. http://dx.doi.org/10.2307/3172514

Chen, F. Y., \& Yu, W. (2011). Research on supervisor support to work-family conflict and job performance for frontline employees in hotel industry. Tourism forum, 4(6), 85-90.

Churchill Jr, G. A., Ford, N. M., \& Walker Jr, O. C. (1976). Organizational climate and job satisfaction in the salesforce. Journal of Marketing Research, 13(4), 323-332. http://dx.doi.org/10.2307/3151014

Hobfoll, S. E. (1989). Conservation of resources: A new attempt at conceptualizing stress. American psychologist, 44(3), 513. http://dx.doi.org/10.1037/0003-066X.44.3.513

Hobfoll, S. E. (2001). The influence of culture, community, and the nested-self in the stress process: Advancing conservation of resources theory. Applied Psychology, 50(3), 337-421. http://dx.doi.org/10.1111/1464-0597.00062

Kahn, R. L., Wolfe, D. M., Quinn, R. P., Snoek, J. D., \& Rosenthal, R. A. (1964). Organizational stress: Studies in role conflict and ambiguity. Oxford, England: John Wiley.

Karatepe, O. M., Uludag, O., Menevis, I., Hadzimehmedagic, L., \& Baddar, L. (2006). The effects of selected individual characteristics on frontline employee performance and job satisfaction. Tourism Management, 27(4), 547-560. http://dx.doi.org/10.1016/j.tourman.2005.02.009

Kim, B. P., Murrmann, S. K., \& Lee, G. (2009). Moderating effects of gender and organizational level between role stress and job satisfaction among hotel employees. International Journal of Hospitality Management, 28(4), 612-619. http://dx.doi.org/10.1016/j.ijhm.2009.04.001

Lee, R. T., \& Ashforth, B. E. (1996). A meta-analytic examination of the correlates of the three dimensions of job burnout. Journal of applied Psychology, 81(2), 123. http://dx.doi.org/10.1016/j.ijhm.2009.04.001

Li, Y. X. (2005). Study on job burnout across three occupational samples: an integrity perspective (Unpublished doctoral dissertation). East China Normal University, Shanghai, China.

MacKenzie, S. B., Podsakoff, P. M., \& Ahearne, M. (1998). Some possible antecedents and consequences of in-role and extra-role salesperson performance. The Journal of Marketing, 87-98. http://dx.doi.org/10.2307/1251745

Maslach, C., \& Jackson, S. E. (1981). The measurement of experienced burnout. Journal of Organizational Behavior, 2(2), 99-113. http://dx.doi.org/10.1002/job.4030020205 
Maslach, C., Jackson, S. E., \& Leiter, M. P. (1996). Maslach burnout inventory manual (3rd ed.). Palo Alto, CA: Consult. Psychol. Press.

Maslach, C., Schaufeli, W. B., \& Leiter, M. P. (2001). Job burnout. Annual review of psychology, 52(1), 397-422. http://dx.doi.org/10.1146/annurev.psych.52.1.397

Piko, B. F. (2006). Burnout, role conflict, job satisfaction and psychosocial health among Hungarian health care staff: A questionnaire survey. International journal of nursing studies, 43(3), 311-318. http://dx.doi.org/10.1016/j.ijnurstu.2005.05.003

Rizzo, J. R., House, R. J., \& Lirtzman, S. I. (1970). Role conflict and ambiguity in complex organizations. Administrative science quarterly, 150-163. http://dx.doi.org/10.2307/2391486

Singh, J. (1993). Boundary role ambiguity: Facets, determinants, and impacts. The Journal of Marketing, 57(2), 11-31. http://dx.doi.org/10.2307/1252024

Singh, J., Goolsby, J. R., \& Rhoads, G. K. (1994). Behavioral and psychological consequences of boundary spanning burnout for customer service representatives. Journal of Marketing Research, 31(4), 558-569. http://dx.doi.org/10.2307/3151883

Tubre, T. C., \& Collins, J. M. (2000). Jackson and Schuler (1985) revisited: A meta-analysis of the relationships between role ambiguity, role conflict, and job performance. Journal of management, 26(1), 155-169. http://dx.doi.org/10.1177/014920630002600104

Wang, H., Li X. X., \& Law, K. S. (2003). The distinction of task performance and contextual performance and their effects on work outcomes. Chinese Journal of Management Science, 11(4), 79-84.

Wen, B. Y. (2011). Do job-satisfaction employees always result in customers satisfaction? On the effect of employees professional dedication. Tourism Tribune, 26(5), 68-76.

Westman, M., Hobfoll, S. E., Chen, S., Davidson, O. B., \& Laski, S. (2004). Organizational stress through the lens of conservation of resources (COR) theory. Research in occupational stress and well-being, 4, 167-220. http://dx.doi.org/10.1016/S1479-3555(04)04005-3

Wright, T. A., \& Bonett, D. G. (1997). The contribution of burnout to work performance. Journal of organizational Behavior, 18(5), 491-499. http://dx.doi.org/10.1002/(SICI)1099-1379(199709) 18:5<491::AID-JOB804>3.0.CO;2-I

Zhang, H., \& Niu, Z. B. (2013). An empirical research on impacts of trait and state optimism on service performance of frontline service employees: Based on the framework of "role stress-burnout-job outcome". Nankai Business Review, 16(1), 110-121.

\section{Copyrights}

Copyright for this article is retained by the author(s), with first publication rights granted to the journal.

This is an open-access article distributed under the terms and conditions of the Creative Commons Attribution license (http://creativecommons.org/licenses/by/3.0/). 